\title{
Characterization of UXO-Like Targets Using Broadband Electromagnetic Induction Sensors
}

\author{
Haoping Huang and I. J. Won
}

\begin{abstract}
We have inverted broadband electromagnetic induction data over an isolated target to determine its electrical conductivity, magnetic permeability, radius, and depth using a sphere model. Studies using synthetic data of a concentric, broadband, electromagnetic sensor indicate that the technique is dependable and produces fast-converging solutions. The geometrical parameters obtained through this technique are very close to true values, and the electric parameters for noise-free data are correct to within a few percent. When $10 \%$ noise is added to the data, the geometric parameters are still well determined, but the electric parameters are poorly resolved, particularly for a sphere that is both conductive and permeable. Tests on the experiment data show that volume-equivalent size and depth to a target can be reasonably estimated for a nonspherical object.
\end{abstract}

Index Terms-Electromagnetic induction (EMI), inversion, sphere, unexploded ordnance (UXO).

\section{INTRODUCTION}

$\mathbf{N}$ EW BROADBAND electromagnetic (EM) sensors, the GEM series by Geophex, Ltd. [1]-[6], have been used successfully at many environmental sites. The GEM-3 sensor [4] in particular, the sensor used for this article, can detect small targets, such as buried unexploded ordnance (UXO) and landmines, providing the highest spatial resolution of any extant technology. By measuring an object's EM induction (EMI) response in a broad band, one can detect and attempt to determine the object's geometry and material composition.

After an object has been detected and suspected as a possible UXO, one may wish to know its size and depth as well as its electric conductivity and magnetic permeability. We wish to characterize the object as precisely as possible so that removal can be safe and efficient. One way to obtain these parameters is to perform an inversion using an assumed geometrical model. To this end, we chose a sphere as a model for buried bombs and landmines since it is simple and its analytic solution is available. Also, a sphere is a reasonable approximation when the object is small and far from the sensor.

Many researchers [7]-[13] have studied the response of a conductive and permeable sphere excited by an alternating magnetic field. Others [14]-[18] have discussed techniques to determine the sphere's location and electrical parameters for various sensors. More recently, Won et al. [5], [6] have studied the sphere's broadband response as a target identification process known as electromagnetic induction spectroscopy (EMIS).

Manuscript received June 27, 2001; revised November 24, 2002. This work was supported in part by the Environmental Security Technology Certification Program (ESTCP) Office in Washington, DC and by the U.S. Army Corps of Engineers Waterways Experiment Station (WES).

The authors are with Geophex, Ltd., Raleigh, NC 27603 USA.

Digital Object Identifier 10.1109/TGRS.2003.809936
This paper describes how we may characterize a UXO-like object by determining its conductivity, permeability, size, and depth using the least squares inversion with singular value decomposition based on a sphere model. At the end, we present our inversion results for a set of broadband EMI data obtained over a test site with many buried UXO-like objects.

\section{THE GEM-3 SENSOR}

To explore EMIS-based target characterization, we have employed the GEM-3 (Fig. 1), a concentric, broadband, electromagnetic sensor designed for subsurface geophysical investigation. Since details for the GEM-3 sensor have been discussed by Won et al. [4], only a summary of the sensors salient features are presented here.

The current GEM-3 operates in a bandwidth from $30 \mathrm{~Hz}$ to $24 \mathrm{kHz}$. The sensing head consists of a pair of concentric, circular coils that transmit a continuous, broadband, digitally controlled, electromagnetic waveform. The two transmitter coils connected in an opposing polarity, with precise dimensions and placement, create a zone of magnetic cavity (viz., an area with a vanishing primary magnetic flux) at the center of the two coils. A magnetic cavity is defined as a region where a directional sensor, placed in a specified orientation, produces zero signal induced from the magnetic field. It has been shown that a magnetic cavity can be created at the center of two concentric, circular, current loops that are electrically connected in a series into one circuit. The GEM-3's receiving coil is placed within this magnetic cavity so that it senses only the weak, secondary field returned from the earth and buried targets.

The GEM-3 is a transmitter-bucked sensor, and its concentric geometry is called a "monostatic" configuration because all coils are colocated. The coils are molded into a single, light, circular disk in a fixed geometry, rendering a very portable package. The disk, along with a handle boom, is made of a Kevlar-skinned foam board. Attached to the other end of the boom is a removable electronic console. The entire unit weighs about $4 \mathrm{~kg}$.

\section{THEORETICAL BACKGROUND}

\section{A. Forward Problem}

The EMI responses of a homogeneous conductive and permeable sphere excited by a dipolar alternating magnetic field are given by Wait [7]-[10], Grant and West [11], Ward [12], Ward and Hohmann [13], and more recently by Won et al. [5], among others. Fig. 2 depicts the geometry of this classical problem. Since the soil effects can be ignored as indicated by Gao et al. [19], the solution for a conductive and permeable sphere in free 

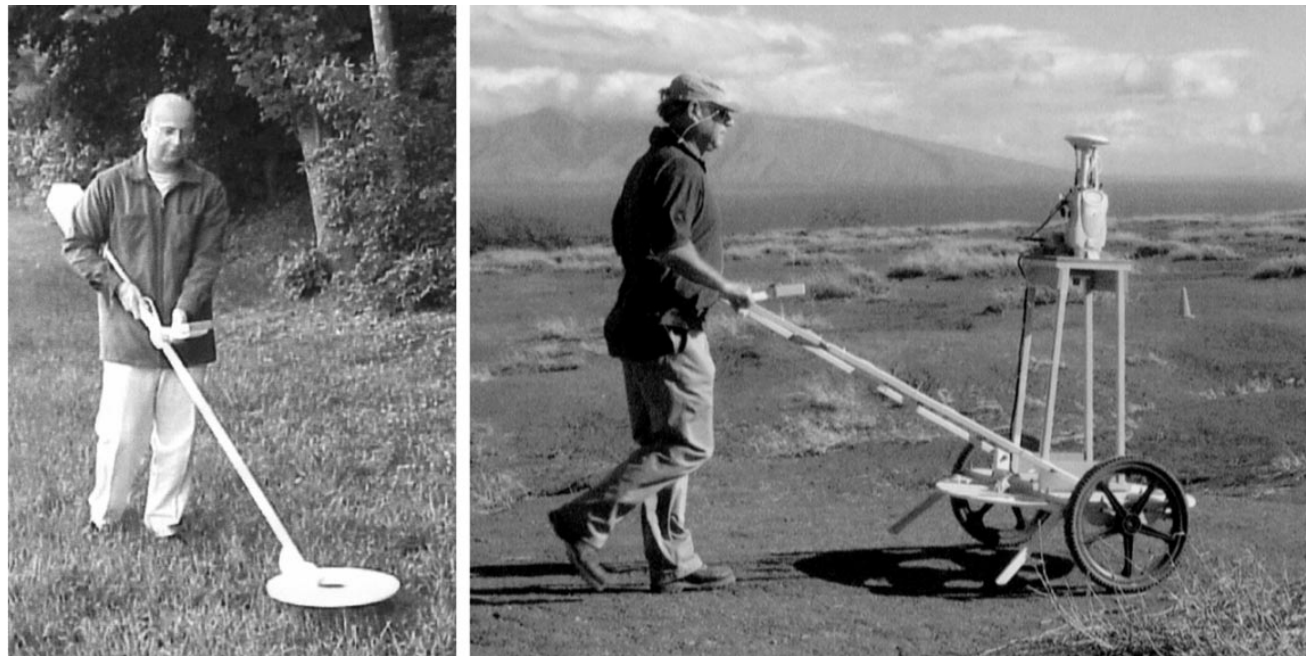

Fig. 1. GEM-3, a monostatic broadband EMI sensor, in operation.

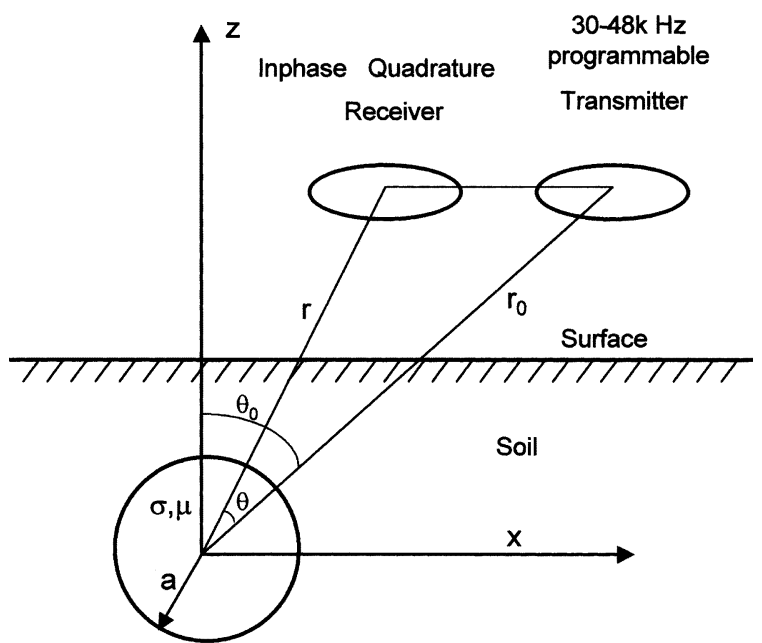

Fig. 2. Geometry of transmitter and receiver coil pairs and sphere. For the case of GEM-3, $\mathbf{r}=\mathbf{r}_{0}$ and $\theta=0$

space is used. The secondary field $H^{2 z}$ at the receiver can be written as

$$
H^{2 z}=\left(H_{r, r}+H_{\theta, r}\right) \cos \theta_{0}-\left(H_{r, \theta}+H_{\theta, \theta}\right) \sin \theta_{0}
$$

where $H_{r, r}$ and $H_{r, \theta}$ are radial and transverse components of the secondary field due to a radial dipole source, and $H_{\theta, r}$ and $H_{\theta, \theta}$ are radial and transverse components of the secondary field due to a transverse dipole source. Adopting the expressions and notations used by Grant and West [11], we can write them as

$$
\begin{aligned}
H_{r, r}= & -\frac{m_{r}}{4 \pi} \sum_{n=1}^{\infty}\left(X_{n}+i Y_{n}\right) \frac{a^{2 n+1}}{\left(r r_{0}\right)^{n+2}} n(n+1) P_{n}(\cos \theta) \\
H_{r, \theta}= & -\frac{m_{r}}{4 \pi} \sum_{n=1}^{\infty}\left(X_{n}+i Y_{n}\right) \frac{a^{2 n+1}}{\left(r r_{0}\right)^{n+2}} n P_{n}^{1}(\cos \theta) \\
H_{\theta, r}= & \frac{m_{\theta}}{4 \pi} \sum_{n=1}^{\infty}\left(X_{n}+i Y_{n}\right) \frac{a^{2 n+1}}{\left(r r_{0}\right)^{n+2}} n P_{n}(\cos \theta) \\
H_{\theta, \theta}= & -\frac{m_{\theta}}{4 \pi} \sum_{n=1}^{\infty}\left(X_{n}+i Y_{n}\right) \frac{a^{2 n+1}}{\left(r r_{0}\right)^{n+2}} \\
& \cdot\left[n^{2} P_{n}\left(\cos (\theta)-\frac{n}{n+1} \cot (\theta) P_{n}^{1}(\cos \theta)\right]\right.
\end{aligned}
$$
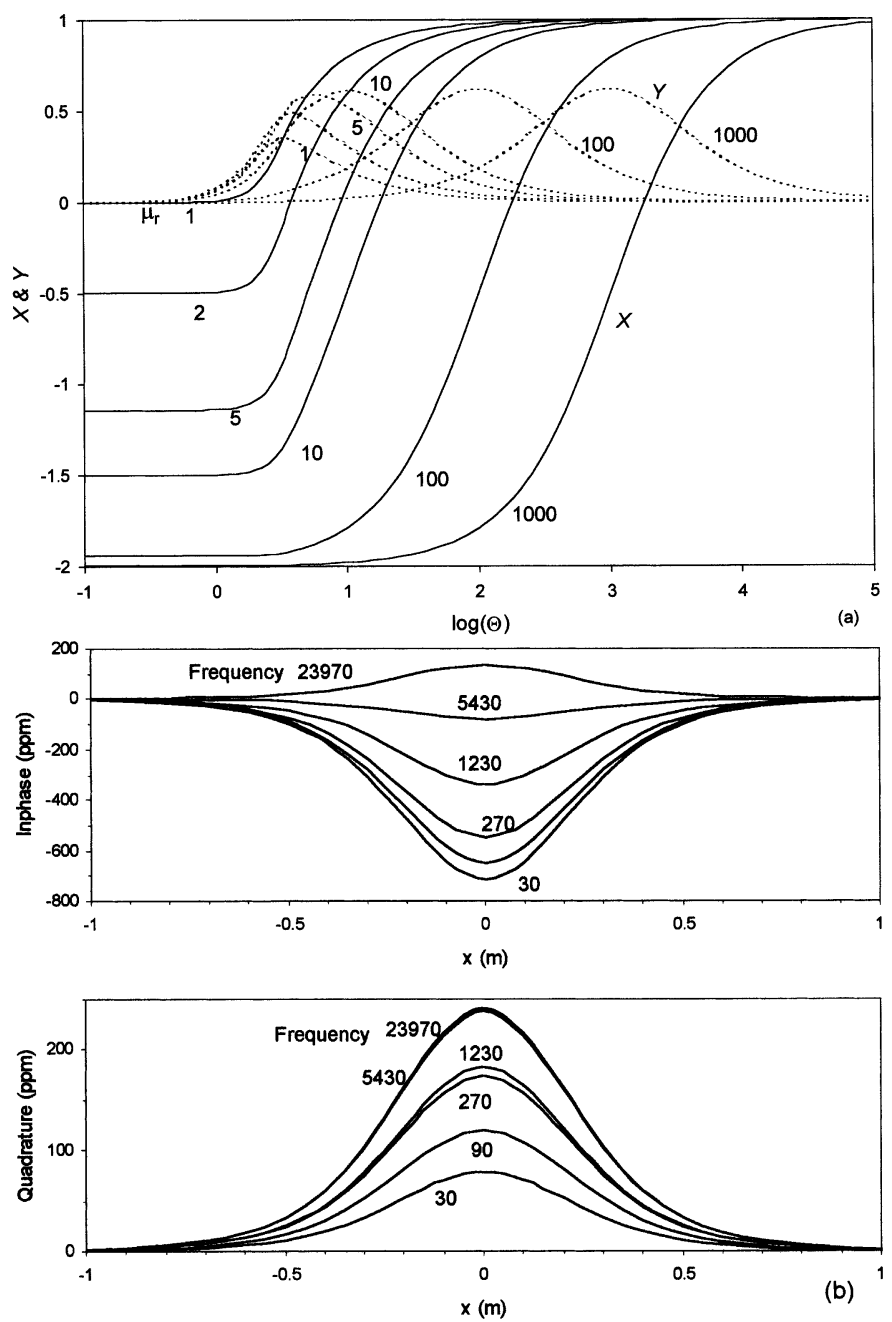

Fig. 3. (a) GEM-3 response of a sphere as a function of the induction number $\Theta$ for various values of the relative magnetic permeability. Solid curves are the inphase component, and dashed curves are the quadrature component. (b) Profiles of inphase and quadrature data for sphere with $10 \mathrm{~cm}$ in radius, depth to the center of sphere of $0.6 \mathrm{~m}$, a conductivity of $10^{6} \mathrm{~S} / \mathrm{m}$, and a relative permeability of 200 .

where $P_{n}$ is the $n$ th-order Legendre polynomial, and $P_{n}^{1}$ is the associated Legendre polynomial. Other variables are defined in Fig. 2. For the case of GEM-3, $\mathbf{r}=\mathbf{r}_{0}$. The complex expression 

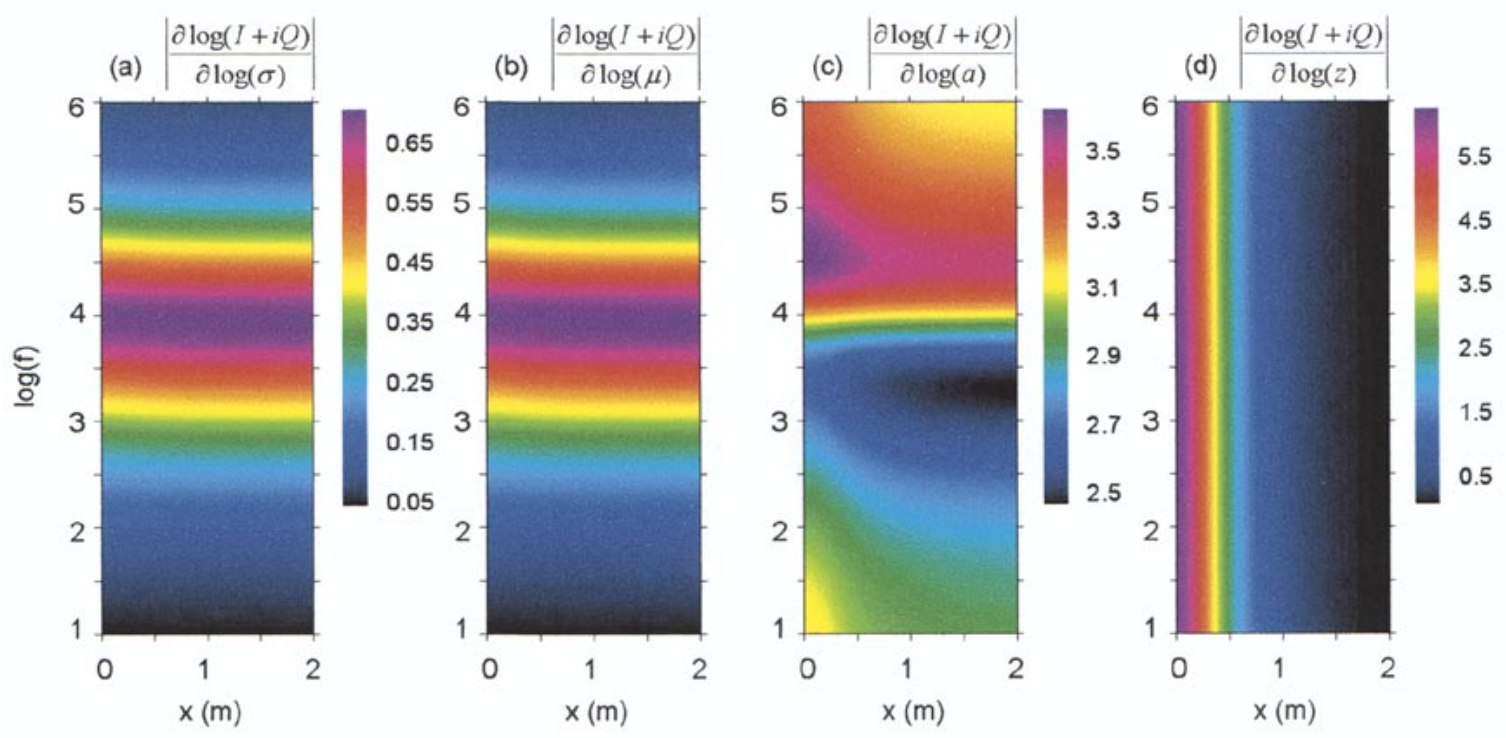

Fig. 4. Magnitude plots of partial derivatives of a sphere response with respect to the model parameters (a) conductivity, (b) relative permeability, (c) radius, and (d) depth to the center of sphere as functions of frequency $f$ and distance $x$. The model parameters are the same as those in Fig. 3(b). Panels (a) and (b) share the same color bar.

$\left(X_{n}+i Y_{n}\right)$ in (2)-(5), called the response function, contains all EM properties and the size of the sphere. The remaining terms are real and are governed only by the relative geometry between the sphere and the sensor locations. The real part of the response function $X_{n}$ generates the inphase response, and the imaginary part $Y_{n}$ generates the quadrature response of the sphere. For a solid, conductive, and permeable sphere, the response function can be shown as

$$
X_{n}+i Y_{n}=\frac{\left[\frac{1}{2}-\mu_{r}(n+1)\right] I_{n+\frac{1}{2}}(k a)+k a I_{n+\frac{1}{2}}^{\prime}(k a)}{\left(\frac{1}{2}+n \mu_{r}\right) I_{n+\frac{1}{2}}(k a)+k a I_{n+\frac{1}{2}}^{\prime}(k a)}
$$

in which $k^{2}=i \omega \mu \sigma$, and $I_{n+(1 / 2)}(k a)$ is the modified spherical Bessel function of the first kind at an order $n+(1 / 2)$ and has a first derivative $I_{n+(1 / 2)}^{\prime}(k a)$.

In order to understand the nature of EMI response of a monostatic, broadband, electromagnetic sensor over a sphere, we plot, in Fig. 3(a), the $X+i Y$ as a function of $\Theta=(\sigma \mu \omega)^{1 / 2} a$ for various values of $\mu_{r}$, the relative permeability or $\mu / \mu_{0}$. Here $\Theta$ is the response parameter; $\sigma$ is the conductivity; and $\omega$ is the angular frequency. The summation procedure continues until $n$ reaches such a number that the differences $\left|X_{n}-X_{n-1}\right|$ and $\left|Y_{n}-Y_{n-1}\right|$ are less than a preset threshold. The plot completely describes the frequency response of a conductive and permeable sphere. At low frequency or resistive limit (small $\Theta)$, both the inphase and quadrature components are small for $\mu_{r}=1$, but the quadrature component is dominant. For $\mu_{r}>1$, the inphase exhibits large negative values and becomes dominant. This is the permeability limit at zero frequency, or the dc magnetic response. In this case, a ferrous sphere is magnetized along the external field lines that are generated by a magnetic dipole transmitter. At high frequency or conductive limit (large $\Theta)$, the inphase is dominant and asymptotically approaches one. The quadrature behaves similarly for both ferrous and nonferrous cases. It peaks at a particular $\Theta$ that is related to the target's physical properties.
The inphase and quadrature components of secondary field at each frequency are expressed, in practice, in units of parts per million (ppm) of the primary field intensity at the receiving coil. For the concentric configuration, $\mathbf{r}=\mathbf{r}_{0}$ and $\theta=0$ in (2)-(5). Fig. 3(b) shows profiles of inphase response $I$ and quadrature response $Q$ for a sphere $10 \mathrm{~cm}$ in radius, $60-\mathrm{cm}$ depth to the sphere center, a conductivity of $10^{6} \mathrm{~S} / \mathrm{m}$, and a relative permeability of 200 , typical for steel. The inphase responses are negative at the lower frequencies and are frequency-dependent, indicating that the targets are both magnetic and conductive. The amplitude of the responses depends very much upon the targets' depths.

\section{B. Inverse Problem}

We use traditional techniques for solving nonlinear inverse problems by minimizing the objective function. Such techniques have been widely used in exploration geophysics and widely described in the literature. The development of inversion programs is not within the scope of this paper. However, a brief outline will be given here. Readers can find more details in [13], [20], and [21].

The data vector $\mathbf{d}$ is defined as a set of measured data $\mathbf{d}=$ $\left[d_{1}, d_{2}, \ldots, d_{N}\right]$, and the parameter vector $\mathbf{p}$ is a set of model parameters $\mathbf{p}=\left[p_{1}, p_{2}, \ldots, p_{M}\right]$, where $N$ is the number of measured data, and $M$ is the number of model parameters. For broadband EM measurements, the set of measured data contains the inphase and quadrature components at each frequency. For a spherical model, the set of model parameters are the conductivity $\sigma$, relative permeability $\mu_{r}$, the radius $a$, and the depth to the center of the sphere $z$.

The functional relationship between the model parameters and the EM responses in (1) is highly nonlinear. To linearize the problem, we expand $H^{2 z}$ in a Taylor series around an initial model parameter vector $\mathbf{p}^{0}$ and neglect higher order terms. Thus, we obtain $\Delta \mathbf{d}=\mathbf{A} \Delta \mathbf{p}$, where $\Delta \mathbf{d}$ is a vector of differences between the measured data and the response of the ini- 

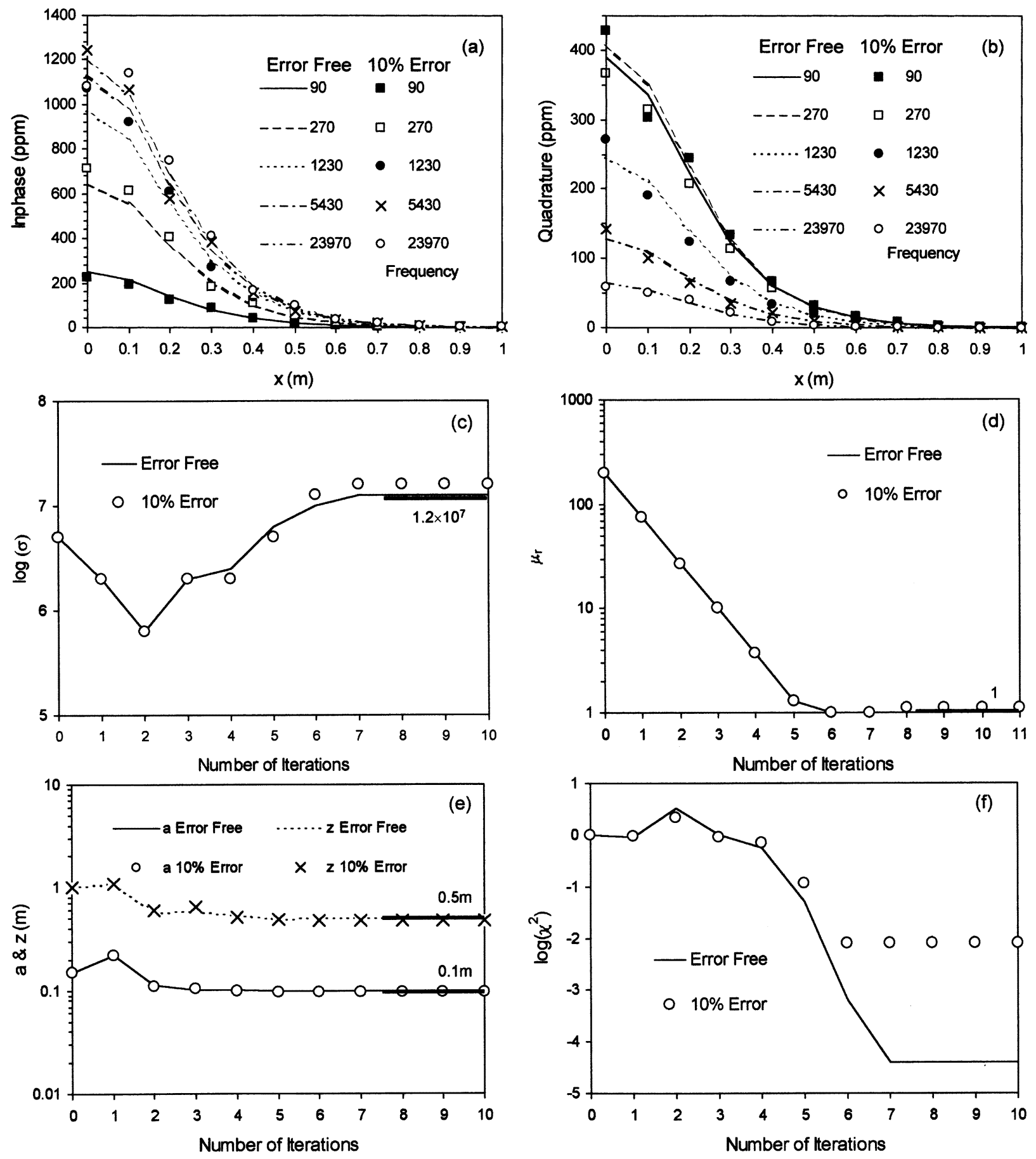

Fig. 5. (a) Inphase and (b) quadrature data at 90 and $270 \mathrm{~Hz}$ and $1.230,5.430$, and $23.970 \mathrm{kHz}$ computed over a sphere $\left(\sigma=1.2 \times 10^{7} \mathrm{~S} / \mathrm{m}, \mu_{r}=1, a=10 \mathrm{~cm}\right.$, and $z=50 \mathrm{~cm}$ ). Convergences of (c) $\sigma$, (d) $\mu_{r}$, (e) $a$ and $z$, and (f) the fitting error are shown as a function of iteration. The curves are for the error-free data, and the symbols are for data with $10 \%$ error added.

tial model, and $\Delta \mathbf{p}$ contains differences between the updated and initial model parameters, $\mathbf{p}$ and $\mathbf{p}^{0} . \mathbf{A}=\left\{\partial d_{i} / \partial p_{j}\right\}$ is an $N \times M$ matrix referred to as the Jacobean matrix, where $i=1,2, \ldots, N, j=1, \ldots, M$. Using singular value decomposition (SVD), we have $\mathbf{A}=\mathbf{U} \boldsymbol{\Lambda} \mathbf{V}^{\mathrm{T}}$, where $\mathbf{U}$ is an $N \times N$ data eigenvector matrix, $\mathbf{V}$ is an $M \times M$ parameter eigenvector, and $\boldsymbol{\Lambda}$ is an $N \times M$ diagonal matrix whose elements $\lambda_{j}$ are the singular values. Then, the model parameter vector correction $\Delta \mathrm{p}$ can be approximately calculated by

$$
\Delta \mathbf{p}=\mathbf{V} \boldsymbol{\Lambda}^{-1} \mathbf{U}^{\mathrm{T}} \Delta \mathbf{d}
$$

where elements in $\boldsymbol{\Lambda}^{-1}$ are $1 / \lambda_{j}$. A small singular value tends to yield a large contribution to $\Delta \mathrm{p}$. This may place a new solution outside the region where the Taylor series expansion is valid, and therefore make the inversion unstable. To stabilize the inverse procedure, we use Marquardt's method, and (7) can be modified as

$$
\Delta \mathbf{p}=\mathbf{V} \boldsymbol{\Lambda}\left(\boldsymbol{\Lambda}^{2}+e^{2} \mathbf{I}\right)^{-1} \mathbf{U}^{\mathrm{T}} \Delta \mathbf{d}
$$

where $\mathbf{I}$ is the identity matrix and $e^{2}$ is the damping parameter. The damping factor is defined as a percentage of the largest 

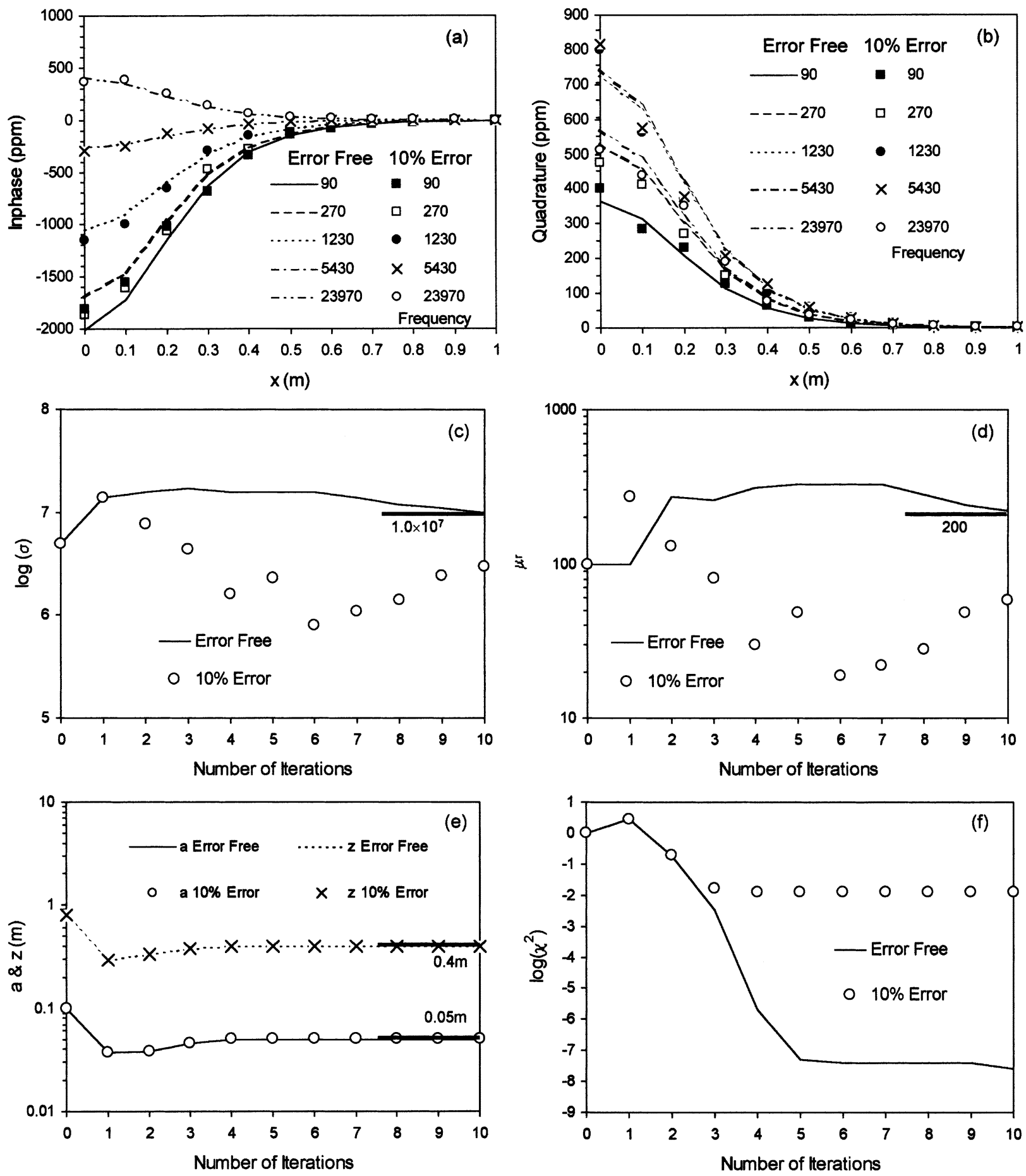

Fig. 6. (a) Inphase and (b) quadrature data at 90 and $270 \mathrm{~Hz}$ and $1.230,5.430$, and $23.970 \mathrm{kHz}$ computed over a sphere $\left(\sigma=10^{7} \mathrm{~S} / \mathrm{m}, \mu_{r}=200, a=5 \mathrm{~cm}\right.$, and $z=40 \mathrm{~cm}$ ). Convergences of (c) $\sigma$, (d) $\mu_{r}$, (e) $a$ and $z$, and (f) the fitting error are shown as a function of iteration. The curves are for the error-free data, and the symbols are for the noisy data.

singular value $\lambda_{1}$. The percentage is large in the beginning of the iteration procedure, and gradually decreases as the model parameters are improved.

An updated model parameter vector at the $k$ th iteration is given by $\mathbf{p}^{\mathrm{k}}=\mathbf{p}^{\mathrm{k}-1}+\Delta \mathbf{p}$. The misfit $\chi^{2}$, given by

$$
\chi^{2}=\frac{1}{M} \sum_{i=1}^{M}\left[d_{i}-H_{i}^{2 z}(\mathbf{p})\right]^{2}
$$

will be minimized. Typically, several iterations are required before an acceptable solution is obtained in terms of minimizing the misfit.

Inversion methods based on the linearization of nonlinear functions depend critically on the ability to estimate the Jacobian matrix. The most common way of computing the partial derivatives is a finite-difference scheme, which is easy to program once a subroutine to do the forward problem is available, and the accuracy of the estimates can be made comparable to the 
analytical solutions. For a central finite difference technique, the partial derivatives are given by

$$
\frac{\partial d_{i}}{\partial p_{j}} \cong \frac{H_{i}^{2 z}\left(p_{j}+\Delta p_{j}\right)-H_{i}^{2 z}\left(p_{j}-\Delta p_{j}\right)}{2 \Delta p_{j}}
$$

where $p_{j}$ is the $j$ th model parameter, and $d_{i}$ is the $i$ th data. Since the EMI data and electric parameters vary over several orders of magnitude, both the data and model parameters are scaled into a log space for the inversion.

The analysis of partial derivatives of responses with respect to the model parameters contributes to a better understanding of the relative importance of model parameters and data. A large value of the partial derivative of response with respect to a model parameter indicates good parametric resolvability, and the associated data will be relatively important for resolving the model parameters. A value close to zero means poor resolvability, and the associated data will be less important. The partial derivatives with respect to the model parameters $|(\partial \log (I+i Q)) /(\partial \log (p))|$ are shown in Fig. 4 as functions of frequency $f$ and distance $x$ from the center of the sphere. The model has the same parameters as that in Fig. 3(b). The GEM-3 has a radial symmetry, and therefore, the spatial responses depend only on its distance from the center of the sphere. It can be seen that the parameters $a$ and $z$ have large partial derivatives and therefore can be determined accurately. The determination of radius $a$ depends mostly on the frequency data and slightly on the spatial data. The depth $z$ relies almost exclusively on spatial data. The data measured over the center of the sphere is the most important in determining depth, and the degree of importance decreases as the distance increases. On the other hand, the estimate of $\sigma$ and $\mu$ can be ambiguous due to small partial derivatives. The resolvability for $\sigma$ and $\mu$ also depends on the sensor bandwidth in the range of $10^{3}$ to $10^{5} \mathrm{~Hz}$.

\section{TEST OF Synthetic DATA}

We first apply the inversion technique to synthetic data. Assume that the GEM-3 operates at five simultaneous frequencies: 90 and $270 \mathrm{~Hz}$ and $1.230,5.430$, and $23.970 \mathrm{kHz}$, and that the horizontal position of the sphere has been determined from profile data. For the GEM-3 configuration, this position always corresponds to the peak response.

It is well known that the result of inversion depends largely on the starting parameters, so a priori knowledge of a target would be important to ensure that iteration converges to the global minimum of the object function. It is safe to assume that the size and depth for UXO-like objects vary within a limited range. For common metals, $\sigma$ varies about two decades from $10^{6}$ to $10^{7}$ and $\mu_{r}$ about four decades from 1 to $10^{4}$.

We first present the inversion results for a sphere having $\sigma=$ $1.2 \times 10^{7} \mathrm{~S} / \mathrm{m}, \mu_{r}=1$ (nonmagnetic), $a=10 \mathrm{~cm}$, and $z=$ $50 \mathrm{~cm}$. Inphase and quadrature data used in the inversion are shown in Fig. 5(a) and (b), in which the sphere is located at $x=0$. We show only a half profile because the response is radially symmetric. The curves represent the noise-free data computed from a forward modeling program, and the symbols show the data with $10 \%$ random noise added. As usual, the profile is oversampled in the hope that any random noise would average out [22].

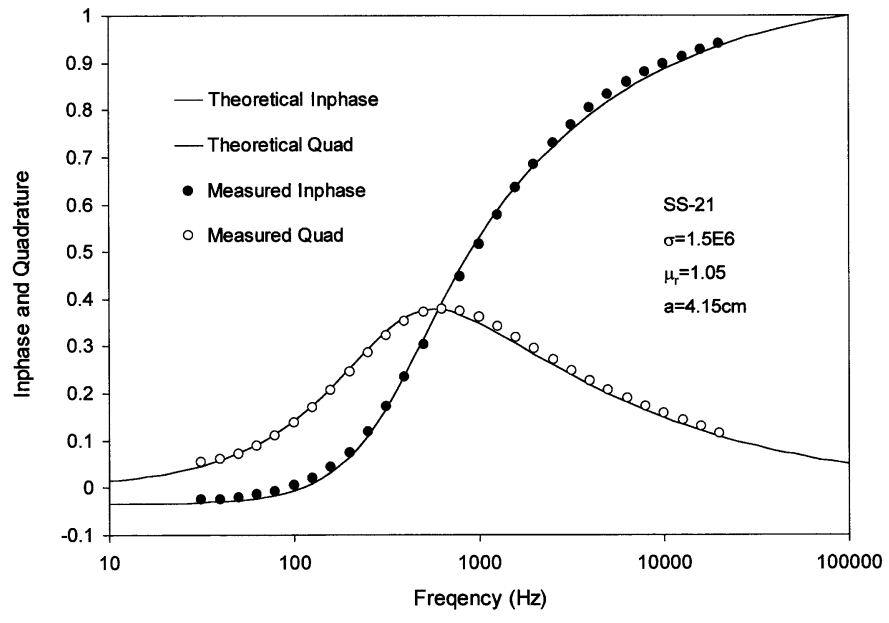

Fig. 7. Measured response (circles) of a 4.15-cm radius stainless steel sphere is fit to the theoretical response (solid lines) to determine its conductivity and permeability

Inversion results for the data are shown in Fig. 5. Fig. 5(c)-(e) illustrates how the model parameters change after each iteration. From a starting model, all parameters steadily approach the true values. $\mu_{r}$ converges rapidly and reaches the correct value after six iterations. $a$ and $z$ approach the true values after six iterations. $\sigma$ converges slowly, and the correct value for noise-free data has been obtained at the seventh iteration. When the inversion is performed using data with $10 \%$ noise, the convergence is almost the same as that for noise-free data, except that the conductivity is slightly overestimated. Fig. 5(f) illustrates the decrease in the fitting error normalized against the starting model in logarithmic space. It is reduced by four orders of magnitude in seven iterations for noise-free data.

Our second synthetic example employs a sphere having $\sigma=$ $10^{7} \mathrm{~S} / \mathrm{m}, \mu_{r}=200, a=5 \mathrm{~cm}$, and $z=40 \mathrm{~cm}$. Fig. 6(a) and (b) illustrates both error-free data and $10 \%$ noise data. The inphase responses are negative at the lower frequencies and frequency-dependent, as should be the case for a magnetic sphere. Fig. 6(c)-(e) illustrates the convergence trends, and Fig. 6(f) illustrates fitting error. All parameters have steadily approached the true model parameters within ten iterations for noise-free data. As before, the geometrical parameters converge faster than the electric parameters. The added noise affects the convergence of $\sigma$ and $\mu_{r}$ more than it does $a$ and $z$.

\section{Test on Experimental Data}

\section{A. Experiment 1. A Metal Sphere in the Air}

We first tested on GEM-3 data obtained above metal spheres suspended in the air. Since $\sigma$ and $\mu_{r}$ of each metal sphere are not known, we determined them by measuring the sphere's GEM-3 spectral response and fitting the data to theoretical spectral response, as shown in Fig. 7, as an example, for a 4.15-cm radius stainless-steel ball.

Fig. 8 shows GEM-3 data for a ferrous sphere, a shotput, measured at five frequencies of 90 and $270 \mathrm{~Hz}$ and $1.230,5.430$, and $23.970 \mathrm{kHz}$. The sphere had a radius of $6.25 \mathrm{~cm}$ ( $2.5 \mathrm{in})$ and was placed at $50.5 \mathrm{~cm}$ below the sensor. The inphase component is negative at the lower frequencies, and the quadrature component 

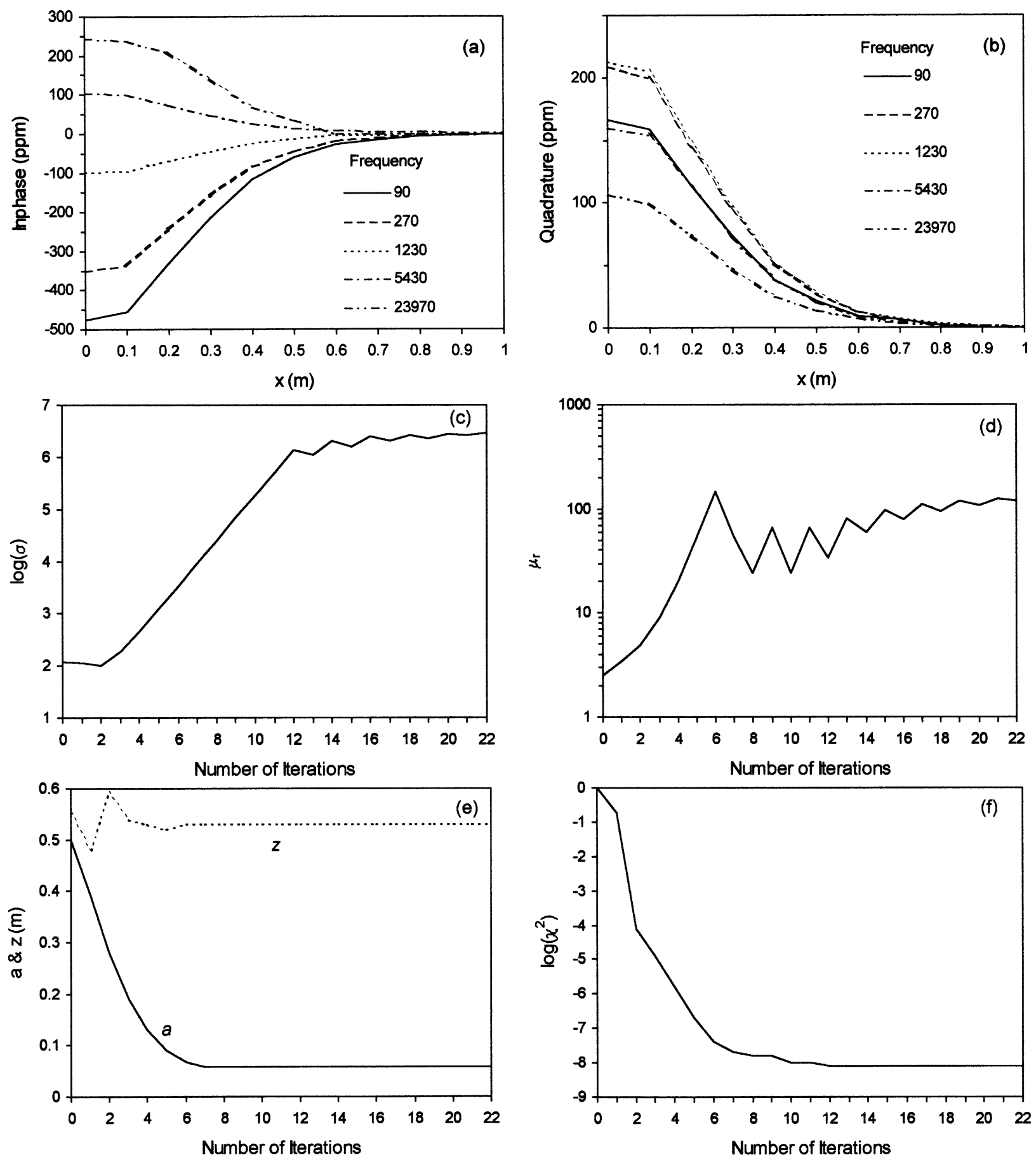

Fig. 8. (a) Inphase and (b) quadrature data at 90 and $270 \mathrm{~Hz}$ and $1.230,5.430$, and $23.970 \mathrm{kHz}$ for a ferrous sphere (a 5 -in diameter shotput) placed at $50.5 \mathrm{~cm}$ below the GEM-3 sensor. The convergences of (c) $\sigma$, (d) $\mu_{r}$, (e) $a$ and $z$, and (f) the fitting error are shown as a function of iteration.

has high amplitude, as it should be for a permeable and conductive sphere. The parameters $a$ and $z$ converge to 5.86 and $53 \mathrm{~cm}$, respectively, after eight iterations. These estimates are within $6 \%$ from their true values. $\sigma$ and $\mu_{r}$ converge to $3 \times 10^{6} \mathrm{~S} / \mathrm{m}$ and 120 , close to the true values. The instability during the iterations indicates that the two electric parameters are partly coupled.

\section{B. Experiment 2. A Metal Cylinder in the Air}

Except for some old cannon balls, the geometry of most UXO is closer to a cylinder than a sphere, we tested the applicability of the inversion method using a cylinder suspended in the air. Fig. 9 shows the GEM-3 data measured above a 5-cm-diameter $37.5-\mathrm{cm}$-long solid steel cylinder placed horizontally. The axis of the cylinder is perpendicular to the profile that crosses the center of cylinder at a height of $49 \mathrm{~cm}$ from the center of the cylinder. The inverted $\sigma$ and $\mu_{r}$ are $2 \times 10^{7} \mathrm{~S} / \mathrm{m}$ and 726, respectively. The radius obtained from the inversion is $5.8 \mathrm{~cm}$, and the depth is $56 \mathrm{~cm}$. When compared with a volume-equivalent sphere, the size is overestimated by $11 \%$. Also, the depth to the center of the target is overestimated by $14 \%$. When the cylinder axis placed horizontally strikes at $45^{\circ}$ to the profile, 

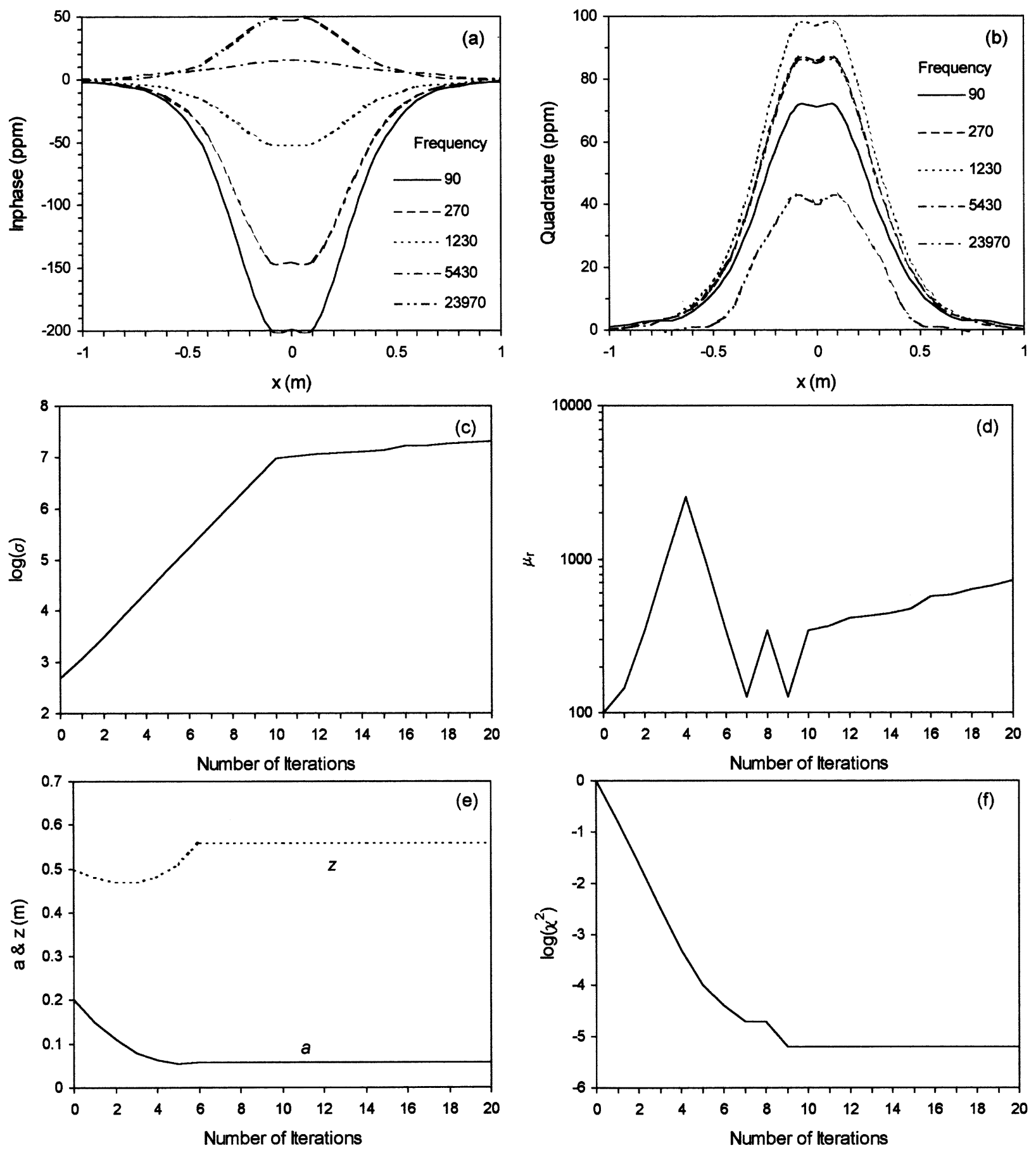

Fig. 9. (a) Inphase and (b) quadrature data at 90 and $270 \mathrm{~Hz}$ and 1.230, 5.430, and $23.970 \mathrm{kHz}$ for a 5-cm-diameter 37.5-cm-long, solid steel cylinder placed horizontally at $49 \mathrm{~cm}$ below the GEM-3 sensor. The profile is perpendicular to the axis of the cylinder. The convergences of (c) $\sigma$, (d) $\mu_{r}$, (e) $a$ and $z$, and (f) the misfit are shown as a function of iteration.

the response curves become slightly wider, and the resulting a and $\mathrm{z}$ are increased to 6.3 and $58.7 \mathrm{~cm}$, respectively.

\section{Experiment 3. Metal Spheres Buried in Clay Soil}

We next buried various metal spheres over a $5 \mathrm{~m} \times 5 \mathrm{~m}$ plot [Fig. 10(a)] in Raleigh, NC. The host soil is dense red clay known as Piedmont Clay, of which resistivity is about $90 \Omega \cdot \mathrm{m}$. Table I shows the buried objects: nine spheres (Brass-230, etc.) and a disk (Disk-83). The spheres, whose radii ranged from $1.15-6.25 \mathrm{~cm}$, were buried at a depth ranging from $5.2-34.3 \mathrm{~cm}$.
We acquired the GEM-3 data over the area at a line spacing of $50 \mathrm{~cm}$ at ten frequencies from $30 \mathrm{~Hz}$ to $23.970 \mathrm{kHz}$. The nominal sensor height was $10 \mathrm{~cm}$ above the ground with an error of $\pm 3 \mathrm{~cm}$. Fig. 10(b) shows the $I$ and $Q$ data at three frequencies over the plot.

Since $\sigma$ and $\mu_{r}$ of each metal sphere are not known, we determined them by measuring the sphere's GEM-3 spectral response and fitting the data to theoretical spectral response. Table I shows the results of inversion based on the GEM-3 data. The last four columns (depth, conductivity, permeability, 

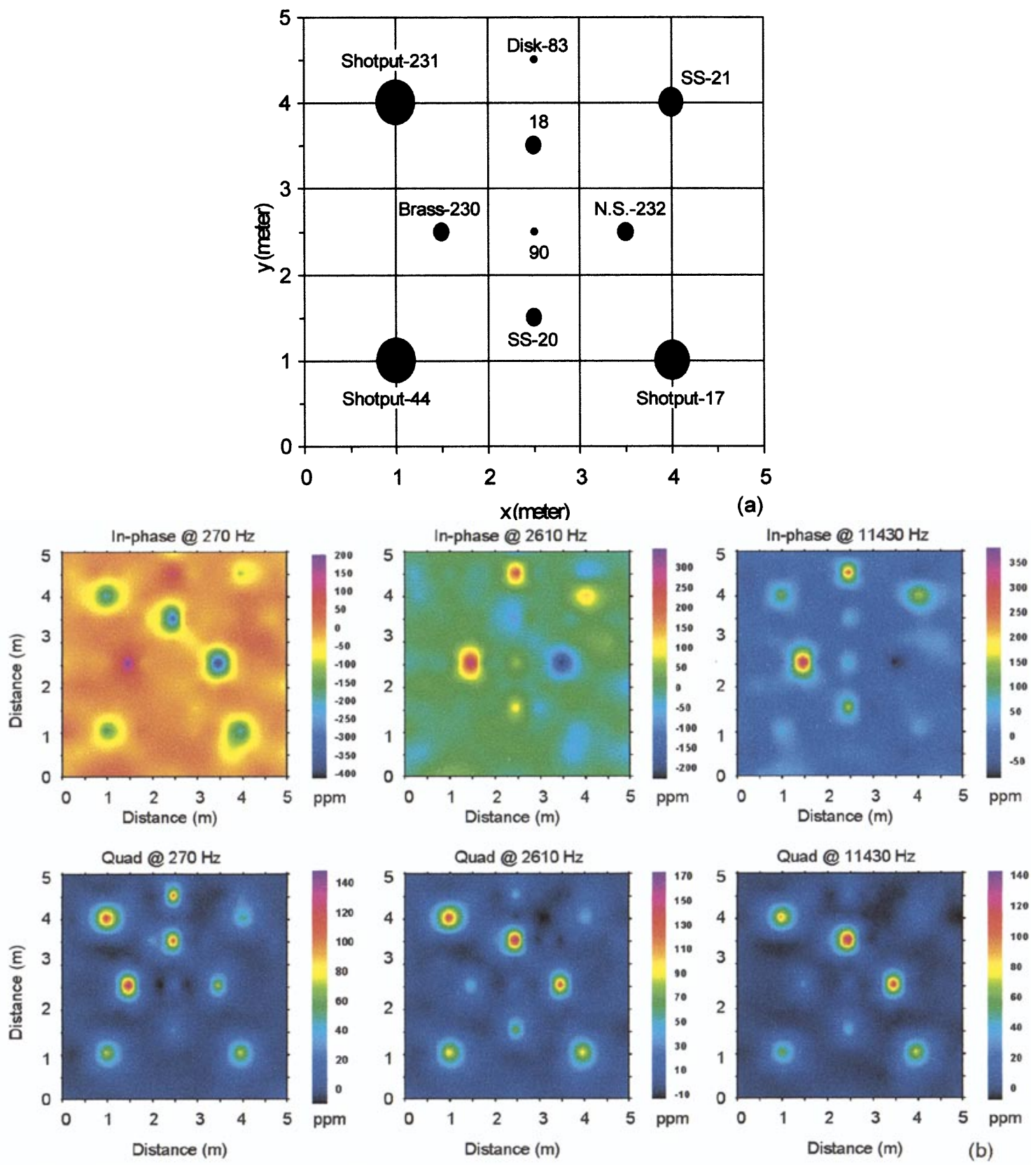

Fig. 10. (a) UXO test site contains nine spheres and one disk. (b) GEM-3 data at $270 \mathrm{~Hz}$ and 2.610 and $11.430 \mathrm{kHz}$ obtained over a $5 \mathrm{~m} \times 5 \mathrm{~m}$ plot where the metal spheres listed in Table I are buried.

TABLE I

Model Parameters and Inversion Results. Numbers With Normal Font Are the True Values, and Those With tHe ITALIC FONT ARE THE INVERTED VALUES

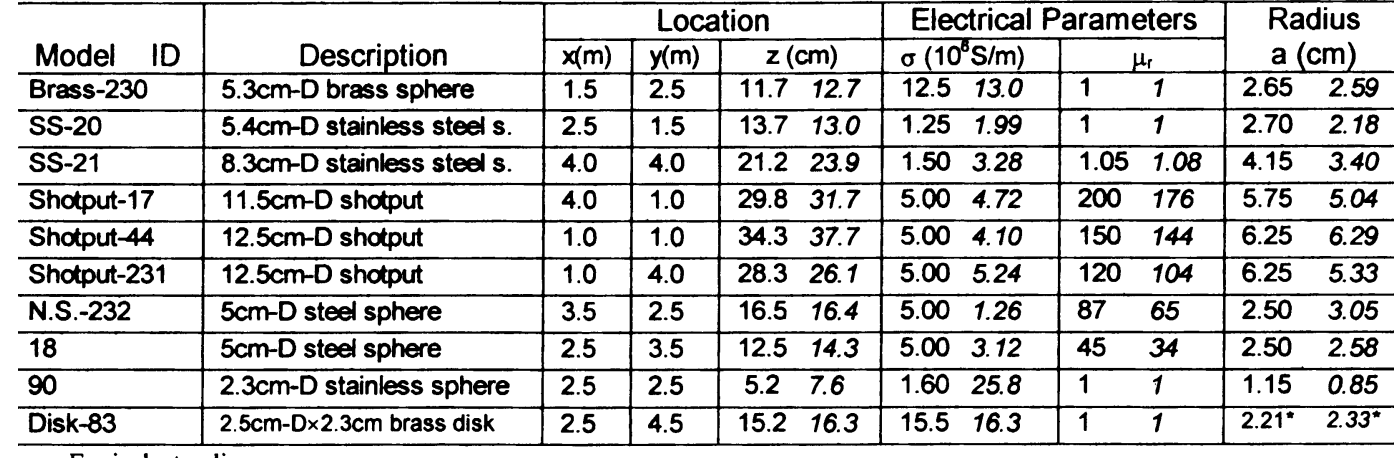



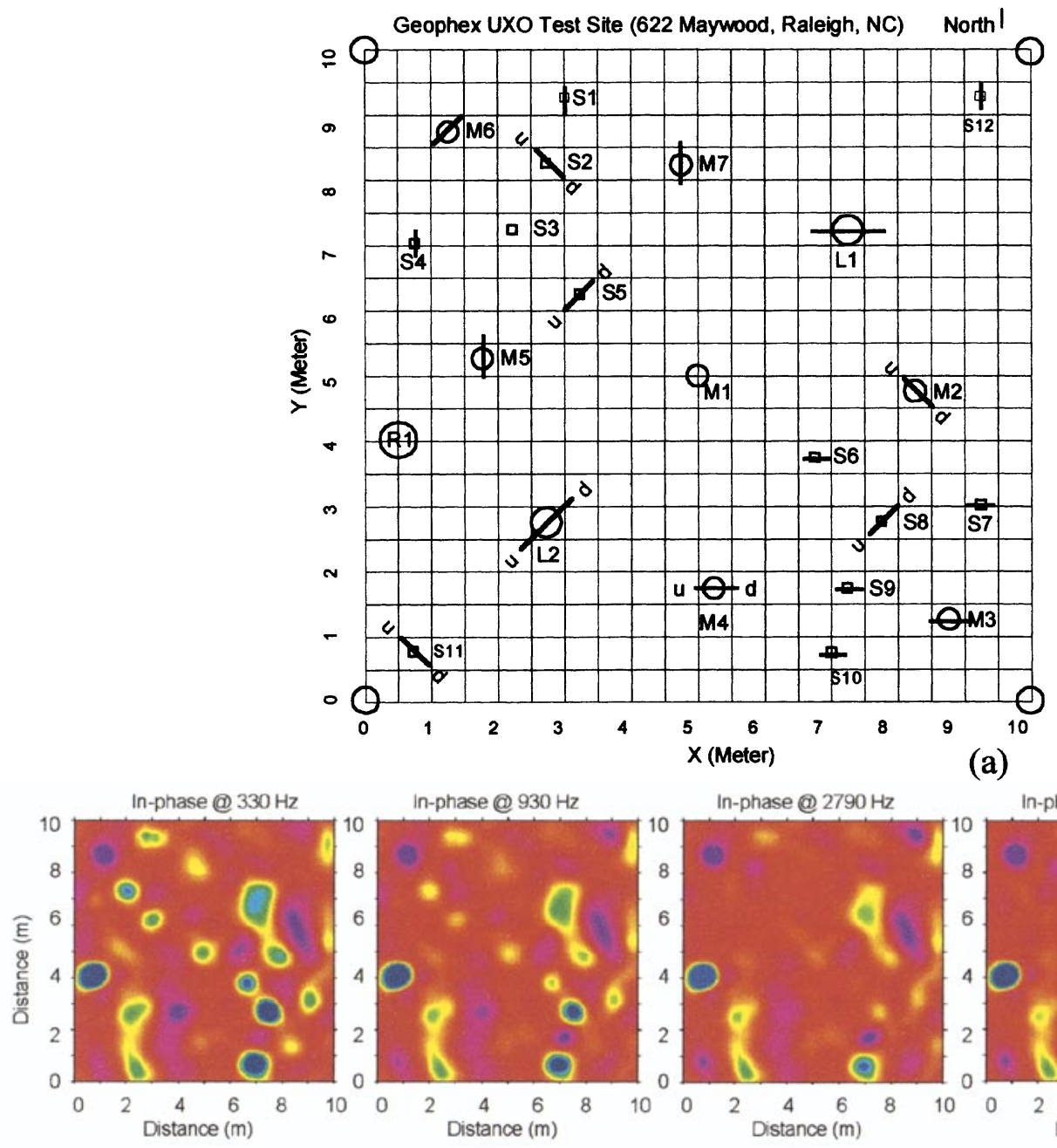

In-phase @ $8190 \mathrm{~Hz}$
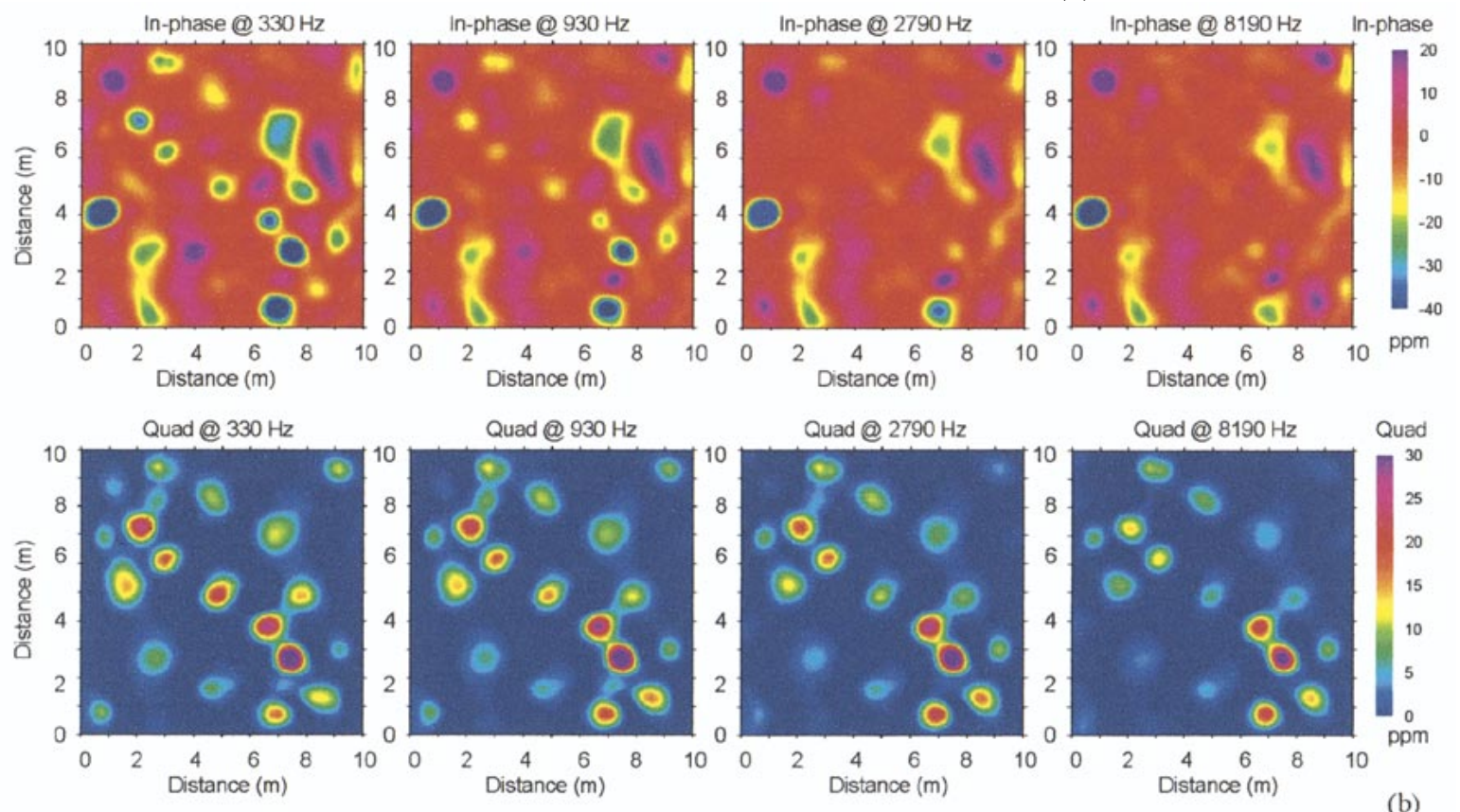

Fig. 11. (a) Geophex UXO test site in Raleigh, NC. The $10 \mathrm{~m} \times 10 \mathrm{~m}$ site contains a total of 21 metal pipes of various diameters and lengths and a diabase boulder. (b) GEM-3 data at 330 and $930 \mathrm{~Hz}$ and 2.790 and $8.190 \mathrm{kHz}$ obtained over the Geophex UXO Test Site.

and radius) compare the true values and the inversion results shown as italic numbers.

\section{Experiment 4. Buried Pipes at Geophex's UXO Test Site}

Our last example comes from the GEM-3 data obtained at a UXO test site, specially designed and constructed by Geophex, Ltd., in Raleigh, NC. The soil is dense red clay. The $10 \mathrm{~m} \times 10 \mathrm{~m}$ test site shown in Fig. 11(a) contains a total of 21 metal pipes of various diameters and lengths. The site also contains a diabase boulder, a magnetic rock. The locations and descriptions of the objects are shown in Table II, in which $z$ is the depth from the surface to the center of the pipes. For vertical and inclined pipes, the table shows the top and center depths. Since we now deal with cylindrical objects and yet are using a spherical model for inversion, we show the volume-equivalent radius for each pipe in the last column of Table II.

We acquired the GEM-3 data at a line spacing of $25 \mathrm{~cm}$. In an effort to simulate practical field conditions, we followed a common survey practice often called dead reckoning: the operator handheld the GEM-3 and walked steadily toward an end-of the-line marker (typically an orange traffic cone) while visually maintaining the sensor height at about $20 \mathrm{~cm}(8$ in) above the ground. (The GEM-3 collects about $8-10$ data points per 
TABLE II

Target Description and InVersion Results. Numbers With Normal Font Are the True Values, and Those With THE ITALIC FonT ARE THE INVERTEd VALUES

\begin{tabular}{|c|c|c|c|c|c|c|c|c|}
\hline Target ID & Description & $x(m)$ & $y(m)$ & $z(\mathrm{~cm})$ & & $\sigma\left(10^{6} \mathrm{~S} / \mathrm{m}\right)$ & $\mu_{\mathrm{T}}$ & $a(\mathrm{~cm})$ \\
\hline L1 & $15.5 \mathrm{~cm}-1 \mathrm{D} \times 50.8 \mathrm{~cm}$ steel pipe, horizontal, E-W & 7.25 & 7.25 & 100 & 92 & 0.27 & $<1000$ & 13 \\
\hline $\mathbf{L}$ & $15.5 \mathrm{~cm}-1 \mathrm{D} \times 50.8 \mathrm{~cm}$ steel pipe, $45 \mathrm{deg} ; \mathrm{SW}$ (up)-NE & 2.75 & 2.75 & $92-110$ & 99 & 0.88 & $<1000$ & 13 \\
\hline M1 & $7.9 \mathrm{~cm}-1 \mathrm{D} \times 45.7 \mathrm{~cm}$ steel pipe, vertical & 5.00 & 5.00 & $47-70$ & 65 & 9.20 & $<1000$ & 8.1 \\
\hline M2 & $7.9 \mathrm{~cm}-1 \mathrm{D} \times 45.7 \mathrm{~cm}$ steel pipe, $45 \mathrm{deg}, N W($ up $)-\mathrm{SE}$ & 8.25 & 4.75 & $64-80$ & 69 & 0.63 & $<1000$ & $\begin{array}{ll}8.1 & 11\end{array}$ \\
\hline M3 & $6.4 \mathrm{~cm}-1 \mathrm{D} \times 30.5 \mathrm{~cm}$ steel pipe, horizontal E-W & 8.75 & 1.25 & 50 & 46 & 11.00 & 406 & 6.2 \\
\hline M4 & $6.4 \mathrm{~cm}-1 \mathrm{D} \times 30.5 \mathrm{~cm}$ steel pipe, $45 \mathrm{deg}, W($ up) $-\mathrm{E}$ & 5.25 & 1.75 & $49-60$ & 57 & 1.10 & 1000 & 6.2 \\
\hline M5 & $7.9 \mathrm{~cm}-1 \mathrm{D} \times 45.7 \mathrm{~cm}$ steel pipe, horizontal, $\mathrm{N}-\mathrm{S}$ & 1.75 & 5.25 & 70 & 74 & 7.40 & 902 & $\begin{array}{ll}8.1 & 10\end{array}$ \\
\hline M6 & $6.4 \mathrm{~cm}-1 \mathrm{D} \times 30.5 \mathrm{~cm}$ aluminum pipe, horiz. SW-NE & 1.25 & 8.75 & 50 & 62 & 59.00 & 4 & 6.2 \\
\hline M7 & $6.4 \mathrm{~cm}-1 \mathrm{D} \times 30.5 \mathrm{~cm}$ steel pipe, horizontal N-S & 4.75 & 8.25 & 60 & 62 & 1.10 & 12 & 6.2 \\
\hline $\mathbf{s} 1$ & $2 \mathrm{~cm}-1 \mathrm{D} \times 10.2 \mathrm{~cm}$ steel pipe, horizontal N-S & 3.00 & 9.25 & 10 & & 1.30 & 15 & 2.0 \\
\hline S2 & $2.3 \mathrm{~cm}-1 \mathrm{D} \times 15.2 \mathrm{~cm}$ alumin. pipe, $45 \mathrm{deg}, \mathrm{NW}(\mathrm{up})-\mathrm{SE}$ & 2.75 & 8.25 & $10-15$ & & 3.60 & 1 & 2.5 \\
\hline S3 & $4.1 \mathrm{~cm}-1 \mathrm{D} \times 15.2 \mathrm{~cm}$ steel pipe, vertical & 2.25 & 7.25 & $22-30$ & 23 & 60.00 & 360 & 3.6 \\
\hline 54 & $4.1 \mathrm{~cm}-1 \mathrm{D} \times 10.2 \mathrm{~cm}$ steel pipe, horizontal N-S & 0.75 & 7.00 & 30 & 25 & 0.49 & 6 & 3.2 \\
\hline S5 & $4.1 \mathrm{~cm}-1 \mathrm{D} \times 15.2 \mathrm{~cm}$ steel pipe, $45 \mathrm{deg}, \mathrm{SW}$ (up)-NE & 3.25 & 6.25 & $25-30$ & & 4.80 & 359 & 3.6 \\
\hline S6 & $4.1 \mathrm{~cm}-1 \mathrm{D} \times 15.2 \mathrm{~cm}$ steel pipe, horizontal E-W & 6.75 & 3.75 & 30 & 30 & 1.50 & 36 & 3.6 \\
\hline S7 & $4.1 \mathrm{~cm}-1 \mathrm{D} \times 10.2 \mathrm{~cm}$ steel pipe, horizontal E-W & 9.25 & 3.00 & 30 & 34 & 0.64 & 30 & 3.2 \\
\hline s8 & $4.1 \mathrm{~cm}-1 \mathrm{D} \times 15.2 \mathrm{~cm}$ steel pipe, $45 \mathrm{deg}, \mathrm{SW}$ (up)-NE & 7.75 & 2.75 & $15-20$ & & 2.40 & 538 & 3.6 \\
\hline S9 & $2.3 \mathrm{~cm}-1 \mathrm{D} \times 15.2 \mathrm{~cm}$ aluminum pipe, horizontal E-W & 7.25 & 1.75 & 15 & 18 & 6.00 & 1 & 2.5 \\
\hline$S 10$ & $2 \mathrm{~cm}-1 \mathrm{D} \times 10.2 \mathrm{~cm}$ steel pipe, horizontal E-W & 7.00 & 0.75 & 10 & 10 & 0.35 & 10 & 2.0 \\
\hline S11 & $2.3 \mathrm{~cm}-1 \mathrm{D} \times 15.2 \mathrm{~cm}$ copper pipe, $45 \mathrm{deg}, \mathrm{NW}(\mathrm{up})-\mathrm{SE}$ & 0.75 & 0.75 & $15-20$ & 14 & 6.10 & 2 & 2.5 \\
\hline S12 & $2.3 \mathrm{~cm}-1 \mathrm{D} \times 15.2 \mathrm{~cm}$ copper pipe, horizontal $\mathrm{N}-\mathrm{S}$ & 9.25 & 9.25 & 15 & 15 & 5.30 & 2 & 2.5 \\
\hline R1 & $30 \times 30 \times 33 \mathrm{~cm}$ diabase boulder & 0.50 & 4.00 & 27 & 30 & .0000016 & 371 & 19.2 \\
\hline
\end{tabular}

second, which results in a data interval of about $15 \mathrm{~cm}$ for a typical walking speed.) The data obtained over each line are then equally distributed along the line, assuming that the walking speed was constant and the line was straight. The maximum position error for such data could be $20 \mathrm{~cm}$ due to uneven walking speed and incorrect walking path. Likewise, the error in the sensor height could be more than $\pm 5 \mathrm{~cm}$. Therefore, the errors associated with the sensor position as well as attitude are the major source of data noise for the inversion process. However, nowadays the GEM-3, particularly with a large-diameter sensing disk, is routinely mounted on a cart along with GPS, which helps reduce the noise caused by sensor height variations and positional errors.

The inphase and quadrature data at four frequencies: 330 and $930 \mathrm{~Hz}$ and 2.790 and $8.190 \mathrm{kHz}$ are shown in Fig. 11(b). The inversion results are shown in Table II as italic numbers. The inverted depths have the largest error of $24 \%$ for target M6, a horizontal aluminum pipe producing a weak anomaly. The inverted depths for vertical and dipping pipes are mostly within their top-center depths. Depth is one of important parameters necessary for identifying a buried target based on EMIS data [23], [24]. The inverted radii a are also very close to the volume-equivalent radii of the pipes. The conductivity $\sigma$ is, in general, higher for the aluminum and copper targets than for the steel targets, although high conductivity is indicated for some steel pipes, especially for both vertical steel pipes L2 and S3. As expected, the relative permeability $\mu_{r}$ is close or equal to one for the aluminum and copper pipes.
As an aside, the magnetic rock R1 causes a strong anomaly on the inphase data at all frequencies and no anomaly on the quadrature, indicating that the target should have high permeability and low conductivity. However, the inverted permeability and conductivity are highly overestimated. This is because the magnetic rock is in the resistive limit as shown in Fig. 3(a) (small $\Theta)$. In this case, the quadrature vanishes and the inphase becomes frequency-independent so that the conductivity and magnetic permeability are not resolvable.

\section{CONCLUSION}

A broadband EMI sensor, such as the GEM-3, provides rich and abundant data; when operated at, say, five frequencies, the sensor generates a total of ten spatial maps ( $I$ and $Q$ data at each frequency) that can be used to detect and characterize buried UXO-like objects. Such a large amount of multifrequency data collected over a single survey renders the method very suitable for inversion of an overdetermined system using least squares technique. Volume-equivalent size of and depth to an object can be reasonably estimated. The depth can be used as an input to an algorithm to identify buried UXO.

\section{REFERENCES}

[1] D. A. Keiswetter, E. Novikova, I. J. Won, T. Hall, and D. Hanson, "Development of a monostatic, multifrequency electromagnetic mine detector," Soc. Opt. Eng., vol. 3079, pp. 831-839, 1997.

[2] D. A. Keiswetter and I. J. Won, "Multifrequency electromagnetic signature of the Cloud Chamber, Nevada Test Site," J. Environ. Eng. Geophys., vol. 2, no. 2, pp. 99-104, 1997. 
[3] I. J. Won, D. A. Keiswetter, G. Fields, and L. Sutton, "GEM-2: A new multifrequency electromagnetic sensor," J. Environ. Eng. Geophys., vol. 1, no. 1, pp. 129-137, 1996.

[4] I. J. Won, D. A. Keiswetter, D. Hanson, E. Novikova, and T. Hall, "GEM-3: A monostatic broadband electromagnetic induction sensor," J. Environ. Eng. Geophys., vol. 2, no. 1, pp. 53-64, 1997.

[5] I. J. Won, D. A. Keiswetter, and E. Novikova, "Electromagnetic induction spectroscopy," J. Environ. Eng. Geophys., vol. 3, no. 1, pp. 27-40, 1998.

[6] I. J. Won, D. A. Keiswetter, and T. H. Bell, "Electromagnetic induction spectroscopy for clearing landmines," IEEE Trans. Geosci. Remote Sensing, vol. 39, pp. 703-709, Apr. 2001.

[7] J. R. Wait, "A conducting sphere in a time-varying magnetic field," Geophysics, vol. 16, pp. 666-672, 1951.

[8] - "A conducting permeable sphere in the presence of a coil carrying an oscillating current," Can. J. Phys., vol. 31, pp. 670-678, 1953

[9] — "Some solutions for electromagnetic problems involving spheroidal, spherical, and cylindrical bodies," J. Res. N.B.S. (Mathematics and Mathematical Physics), vol. 64B, pp. 15-32, 1959.

[10] — - "On the electromagnetic response of a conducting sphere to a dipole field," Geophysics, vol. 25, pp. 619-658, 1960.

[11] F. S. Grant and G. F. West, Interpretation Theory in Applied Geophysics. New York: McGraw-Hill, 1965.

[12] S. H. Ward, "Electromagnetic Theory for Geophysical Applications," in Mining Geophysics, S. H. Ward, Ed: Soc. Exploration Geophysicists, 1967, vol. 2, Theory, pp. 13-196.

[13] S. H. Ward and G. W. Hohmann, "Electromagnetic theory for geophysical applications," in Electromagnetic Methods in Applied Geophysics, M. N. Nabighian, Ed: Soc. Exploration Geophysicists, 1988, vol. 1, pp. 130-311.

[14] S. H. Ward, "Unique determination of conductivity, susceptibility, size, and depth in multifrequency electromagnetic exploration," Geophysics, vol. 24 , pp. 531-546, 1959.

[15] G. S. Lodha and G. F. West, "Practical airborne EM (AEM) interpretation using a sphere model," Geophysics, vol. 41, pp. 1157-1169, 1976.

[16] S. S. Rai and S. K. Verma, "Quantitative interpretation of horizontal loop electromagnetic measurements using a permeable sphere model," Geophys. Prospect., vol. 30, pp. 486-500, 1982.

[17] H. Huang and W. Wang, "Inversion of time-domain airborne electromagnetic data," Chin. J. Geophys., vol. 33, pp. 117-132, 1990.

[18] H. Huang and R. Zhu, "Interpretation method of the time-domain airborne electromagnetic response above a conducting and permeable spherical ore body," J. Changchun College Geol., no. 1, pp. 107-116, 1984.

[19] P. Gao, L. Collins, P. M. Garber, N. Geng, and L. Carin, "Classification of landmine-like metal targets using wideband electromagnetic induction," IEEE Trans. Geosci. Remote Sensing, vol. 38, pp. 1352-1361, May 2000.
[20] C. L. Lawson and R. J. Hanson, Solving Least-Squares Problems. Upper Saddle River, NJ: Prentice-Hall, 1974.

[21] W. Menke, Geophysical Data Analysis-Discrete Inverse Theory. New York: Academic, 1984

[22] J. R. Inman, J. Ryu, and S. H. Ward, "Resistivity inversion," Geophysics, vol. 38, pp. 1088-1108, 1973.

[23] S. J. Norton and I. J. Won, "Identification of buried unexploded ordnance from broadband electromagnetic induction data," IEEE Trans. Geosci. Remote Sensing, vol. 39, pp. 2253-2261, Oct. 2001.

[24] S. J. Norton, I. J. Won, and E. R. Cespedes, "Ordnance/clutter discrimination based on target eigenvalue analysis," Subsurface Sensing Tech. Appl., vol. 2, pp. 285-298, 2001.

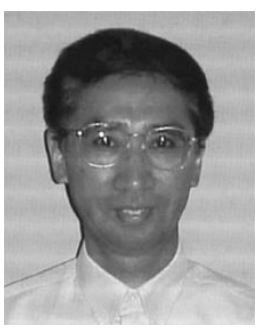

Haoping Huang received the B.S. and M.S. degrees in geophysics from Changchun University of Earth Sciences, Changchun, China.

$\mathrm{He}$ is currently a Research Geophysicist at Geophex, Ltd., Raleigh, NC. He was a Professor of geophysics at Changchun University of Earth Sciences from 1982 to 1992. From 1987 to 1988, he was a Visiting Scholar at Brown University, Providence, RI. From 1993 to 1999, he was a Research Scientist at Geoterrex-Dighem, Toronto, ON, Canada. His current research focuses on electromagnetic methods in unexploded ordnance detection and discrimination. He has published numerous papers on airborne resistivity mapping, electromagnetic data processing, inversion, numerical modeling, digital signal processing, and other interpretation methods.

Mr. Huang is a member of the Society of Exploration Geophysics and the Australian Society of Exploration Geophysicists.

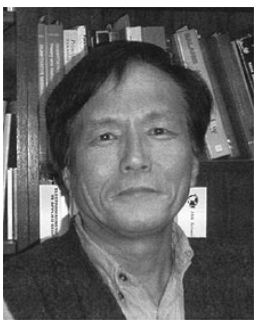

I. J. Won received the B.S. degree in mining engineering from Seoul National University, Seoul, Korea, in 1967, and the M.S. and Ph.D. degrees in geophysics from Columbia University, New York, in 1971 and 1973, respectively.

He is currently President of Geophex, Ltd., Raleigh, NC. From 1976 to 1989, he was Assistant Professor, Associate Professor, and Professor of geophysics at North Carolina State University, Raleigh. He has published over 100 research and review articles in journals and books. 